\title{
Fatores Protetivos e de Risco na Transição entre o Acolhimento
}

\author{
Institucional e a Vida Adulta
}

\author{
Luciana Cassarino-Perez* \\ Universidade Federal do Rio Grande do Sul - UFRGS, Porto Alegre, RS, Brasil \\ ORCID: http://orcid.org/0000-0003-4075-2832 \\ Carme Montserrat** \\ Universitat de Girona, Catalunha, Espanha \\ ORCID: http://orcid.org/0000-0001-5062-1903 \\ Jorge Castellá Sarriera*** \\ Universidade Federal do Rio Grande do Sul - UFRGS, Porto Alegre, RS, Brasil \\ ORCID: http://orcid.org/0000-0001-8297-4957
}

\section{RESUMO}

Este estudo teve por objetivo identificar os fatores de proteção e de risco envolvidos no processo de transição entre o acolhimento institucional e a vida adulta. Participaram 13 jovens entre 18 e 24 anos, de ambos os sexos, egressos do sistema de proteção da cidade de Curitiba, no sul do Brasil. Cinco cuidadores também participaram, representando cada uma das unidades de acolhimento de onde os jovens provieram. Os dados foram coletados por meio de entrevistas em profundidade e submetidos à análise temática. Os temas e subtemas identificados dentro de dois eixos temáticos (fatores de proteção e fatores de risco) atravessam diferentes níveis contextuais e revelam um desequilíbrio que dificulta o processo de transição. Conclui-se que, além da maior observância às políticas e diretrizes já existentes, é necessário formular programas novos e específicos para esses jovens, alicerçados na concepção de que eles próprios devem ser os protagonistas de suas trajetórias.

Palavras-chave: acolhimento institucional, transição para a vida adulta, fatores de proteção, fatores de risco.

\section{Protective and Risk Factors During Transition from Care to Independent}

\section{Living}

\begin{abstract}
The study aimed to identify protective and risk factors involved in the transition process from residential care to independent living. Participants were 13 young people from 18 to 24 years old, man and women, who aged out of care in the city of Curitiba, south of Brazil. A total of five caregivers also participated, each representing one of the residential centers where those young people used to live. Data were collected with in depth semi structured interviews and
\end{abstract}


analyzed through thematic analysis. The themes and subthemes, identified in two thematic axes (protective factors and risk factors), permeate different contexts and disclose an imbalance that hinders the transition process. We conclude that, in addition to compliance of existing social policies, it is necessary to create new and specific programs for young people aging out of care, based on a youth-centered approach.

Keywords: residential care, transition to adulthood, protective factors, risk factors.

\title{
Factores Protectores y de Riesgo en la Transición entre Hogares de Acogida
}

\author{
y la Vida Adulta
}

\section{RESUMEN}

Este estudio tuvo por objetivo identificar los factores de protección y de riesgo implicados en el proceso de transición entre el acogimiento institucional y la vida adulta. Participaron 13 jóvenes entre 18 e 24 años, de ambos sexos, egresados del sistema de protección de la ciudad de Curitiba, en el sur de Brasil. Cinco cuidadores también participaron, representando cada uno de los hogares de acogida donde vivieron esos jóvenes. Los datos fueron recogidos a través de entrevistas en profundidad y sometidos a análisis temático. Los temas y subtemas, identificados dentro de dos ejes temáticos (factores de protección y factores de riesgo), atraviesan distintos niveles contextuales y demuestran un desequilibrio que dificulta el proceso de transición. Se concluye que, además de cumplir las políticas y directrices ya existentes, es necesario formular programas nuevos y específicos para esta población, considerando que los propios jóvenes deben ser los protagonistas de sus trayectorias.

Palabras clave: hogares de acogida, transición a la adultez, factores de protección, factores de riesgo.

Atualmente no Brasil existem diferentes modalidades de transição para a vida adulta. As trajetórias já não são tão lineares como antigamente, e eventos como o casamento e a chegada dos filhos podem anteceder a saída da casa dos pais (Camarano, 2006). Na contramão dessa tendência atual estão os adolescentes acolhidos pelo sistema de proteção. Pela necessidade de deixarem as instituições ao completarem a maioridade, estes transitam da condição de adolescentes a adultos forçadamente, muitas vezes sem o preparo e apoio social necessários (Martinez \& Soares-Silva, 2008; Rosa, Nascimento, Matos, \& Santos, 2012).

De acordo com Greeson (2013), ao se emanciparem, adolescentes acolhidos, além de não contarem com apoio de adultos de referência, não apresentam habilidades para vida cotidiana como cozinhar, limpar, administrar finanças, usar transporte público e etc. $\mathrm{O}$ despreparo e o desamparo têm consequências imediatas negativas, como o desemprego, o 
abandono dos estudos e o envolvimento em comportamentos de risco (Bender, Yang, Ferguson, \& Thompson, 2015; Courtney \& Hook, 2017; Forsman, Brännstöm, Vinnerljung, \& Hjerm, 2016). Às consequências negativas somam-se a escassez de oportunidades oferecidas a esses jovens, os contextos adversos nos quais vivem e a falta de estratégias de enfrentamento e de suporte social. Como resultado acabam por traçar uma trajetória de desvantagens e dependência persistentes ao longo dos anos (Greeson, 2013).

Se por um lado, as pesquisas revelam as condições e contextos adversos em que adolescentes acolhidos transitam para a vida adulta, por outro, estudos têm apontado as possibilidades de superação dessas adversidades, investigando aspectos de resiliência nessa população. A superação de adversidades por meio da manifestação de processos de resiliência está marcada pela variabilidade individual e pela interação entre os fatores de risco e de proteção (Masten, 2001). Fatores de risco são eventos negativos que podem aumentar a probabilidade de ocorrência de problemas físicos, sociais ou emocionais (Poletto \& Koller, 2006), enquanto que fatores de proteção são aspectos que modificam e melhoram a resposta do sujeito aos perigos que podem comprometer o desenvolvimento (Rutter, 1985).

Para adaptarem-se às situações de estresse envolvidas no processo de transição entre o acolhimento institucional e a vida adulta é fundamental que os jovens recebam apoio social (Hass \& Graydon, 2009; Neal, 2017; Wojciak, McWey, \& Waid, 2018). O apoio social se caracteriza pelo conjunto de sistemas e pessoas significativas que compõe os elos de relacionamento recebidos e percebidos pelo sujeito (Brito \& Koller, 1999). Essa importante fonte de resiliência pode ser dividida funcionalmente em apoio emocional (relações disponíveis de afeto e confiança); apoio instrumental (ajuda e assistência para realizar tarefas); e apoio informacional (disponibilidade de orientação e aconselhamento) (Wills, Blechman, \& McNamara, 1996).

Falta de apoio social e de preparo para atividades de vida cotidiana, além da baixa escolaridade e problemas de saúde mental, são os principais fatores de risco envolvidos na transição para a vida adulta de acordo com pesquisas com jovens egressos do sistema de proteção (Greeson, 2013; Scannapieco, Smith, \& Blakeney-Strong, 2016; Sulimani-Aidan, 2017). Por outro lado, a presença de adultos de referência e outras fontes de apoio social, assim como a continuidade dos estudos, funcionam como fatores de proteção para estes jovens (Courtney, Hook, \& Lee, 2012). Outros fatores protetivos são a participação em programas que favoreçam a inserção comunitária e o papel ativo do adolescente na tomada de decisões sobre seu futuro (Nesmith, 2017). 
Os principais fatores influenciadores do processo de transição levantados por estudos recentes estão relacionados a características pessoais dos jovens (otimismo, autoestima, altruísmo, autonomia, funcionamento cognitivo) e a influências do meio (apoio social, funcionamento do sistema de proteção, programas de preparação oferecidos) (Amstadter, Moscati, Maes, Myers, \& Kendler, 2016; Libório \& Ungar, 2010; Pinheiro, 2004). O Paradigma Ecológico aplicado a Psicologia Comunitária tem contribuído amplamente para a compreensão das transições típicas do desenvolvimento humano, justamente por entender que o indivíduo e o meio compõem uma unidade indissolúvel (Sarriera, 2014a; Kelly, 1986). De acordo com este paradigma, o meio é concebido por uma série de estruturas concêntricas cujo núcleo se denomina microssistema. Nesta estrutura nuclear, se dão as atividades, papéis, e relações pessoais de cada indivíduo. Englobando o microssistema estão o mesossitema, composto das interações entre os diversos microssistemas, e o exosistema, composto pelos ambientes nos quais o indivíduo não é participante ativo, mas que interferem no seu desenvolvimento. A estrutura mais ampla, o macrossistema, abrange todas as outras e agrega ao modelo os sistemas cultural, político, econômico e ideológico (Sarriera, 2014a).

As transições típicas do desenvolvimento humano, ou "transições ecológicas", ocupam lugar de destaque no Paradigma Ecológico. Uma transição ecológica provoca alterações comportamentais e mudanças na percepção de si mesmo e dos outros. É através delas que o indivíduo se adapta e busca o equilíbrio entre suas expectativas e as oportunidades que o meio lhe oferece, favorecendo ou prejudicando o desenvolvimento, dependendo das crenças, recursos e habilidades que possuí (Sarriera, 1999).

A transição entre acolhimento institucional e a vida adulta é um processo permeado por inúmeros desafios para os quais os adolescentes, ao serem desligados, não se encontram preparados e amparados. No cenário nacional, ainda são necessários mais esforços para clarificar as necessidades dos jovens nesse processo, bem como os aspectos que favorecem uma transição bem-sucedida. Por essas razões, à luz do Paradigma Ecológico, tem-se como objetivo geral conhecer como ocorre o processo de transição entre o acolhimento institucional e a vida adulta, do ponto de vista dos jovens desligados por maioridade e de cuidadores de instituições de acolhimento no município de Curitiba. Especificamente, este estudo pretende identificar quais são os fatores de risco e os fatores de proteção envolvidos nesse processo a fim de contribuir para melhorias nos serviços e políticas públicas destinadas a essa população. 


\section{Método}

\section{Participantes}

Participaram 13 jovens entre 18 e 24 anos, de ambos os sexos, egressos do sistema de proteção da cidade de Curitiba. Na Tabela 1, estão descritos os dados sociodemográficos. Participaram também cinco cuidadores, sendo um representante de cada uma das instituições das quais os jovens provieram. Dentre os cuidadores, quatro eram mulheres e um homem que exerciam as seguintes funções dentro das instituições: assistente social, educador ou diretor da unidade. A amostra foi selecionada por conveniência. Os critérios de inclusão para os jovens foram: (1) ter entre 18 e 24 anos; (2) ter vivido pelo menos 18 meses em uma ou mais unidades de acolhimento; e (3) ter sido desligado da instituição com 16 anos ou mais. Já os cuidadores deveriam ter pelo menos 12 meses de experiência em unidades de acolhimento e terem sido indicados como adulto de referência por pelo menos um dos jovens. 
Tabela 1

Características Sociodemográficas dos Jovens

\begin{tabular}{|c|c|c|c|c|c|c|c|}
\hline \multirow[t]{2}{*}{ Jovem } & \multicolumn{3}{|c|}{ Idade (anos) } & \multirow[t]{2}{*}{ Sexo } & \multirow[t]{2}{*}{ Escolaridade } & \multirow[t]{2}{*}{ Ocupação } & \multirow[t]{2}{*}{ Moradia } \\
\hline & Atual & Entrada & Saida & & & & \\
\hline J1U1 & 24 & 14 & 19 & Masculino & $\begin{array}{l}\text { Médio } \\
\text { Incompleto }\end{array}$ & Educador & $\begin{array}{c}\text { Casa } \\
\text { alugada }\end{array}$ \\
\hline J2U1 & 24 & 2 & 18 & Masculino & $\begin{array}{l}\text { Superior } \\
\text { Incompleto }\end{array}$ & Educador & $\begin{array}{l}\text { Casa de } \\
\text { familiar }\end{array}$ \\
\hline J3U1 & 19 & 13 & 17 & Masculino & $\begin{array}{l}\text { Médio } \\
\text { Completo }\end{array}$ & Educador & $\begin{array}{l}\text { Casa de } \\
\text { familiar }\end{array}$ \\
\hline J4U1 & 22 & 6 & 18 & Masculino & $\begin{array}{l}\text { Superior } \\
\text { Incompleto }\end{array}$ & $\begin{array}{l}\text { Assistente } \\
\text { administrativo }\end{array}$ & $\begin{array}{c}\text { Casa } \\
\text { alugada }\end{array}$ \\
\hline J5U3 & 21 & 10 & 16 & Feminino & $\begin{array}{l}\text { Médio } \\
\text { Incompleto }\end{array}$ & Serviços Gerais & $\begin{array}{c}\text { Casa } \\
\text { alugada }\end{array}$ \\
\hline J6U1 & 20 & 7 & 18 & Masculino & $\begin{array}{l}\text { Superior } \\
\text { Incompleto }\end{array}$ & Ator & $\begin{array}{l}\text { Casa de } \\
\text { amigo }\end{array}$ \\
\hline $\mathrm{J} 7 \mathrm{U} 2$ & 18 & 1 & 18 & Masculino & $\begin{array}{l}\text { Médio } \\
\text { Incompleto }\end{array}$ & Estudante & Repüblica \\
\hline J8U4 & 18 & 12 & 18 & Feminino & $\begin{array}{l}\text { Médio } \\
\text { Incompleto }\end{array}$ & Estudante & Repüblica \\
\hline J9U4 & 19 & 13 & 18 & Feminino & $\begin{array}{l}\text { Médio } \\
\text { Incompleto }\end{array}$ & Atendente & República \\
\hline J10U5 & 20 & 14 & 18 & Feminino & $\begin{array}{l}\text { Médio } \\
\text { Completo }\end{array}$ & Desempregada & $\begin{array}{c}\text { Casa } \\
\text { alugada }\end{array}$ \\
\hline $\mathrm{J}_{11 \mathrm{U}}$ & 19 & 12 & 17 & Feminino & $\begin{array}{l}\text { Médio } \\
\text { Completo }\end{array}$ & Desempregada & $\begin{array}{c}\text { Casa } \\
\text { alugada }\end{array}$ \\
\hline J12U1 & 19 & 9 & 17 & Masculino & $\begin{array}{l}\text { Médio } \\
\text { Incompleto }\end{array}$ & Desempregado & $\begin{array}{l}\text { Casa de } \\
\text { familiar }\end{array}$ \\
\hline J13U5 & 19 & 1 & 16 & Feminino & $\begin{array}{l}\text { Médio } \\
\text { Incompleto }\end{array}$ & Desempregada & $\begin{array}{c}\text { Casa } \\
\text { alugada }\end{array}$ \\
\hline
\end{tabular}

Nota. Os jovens estão identificados pela inicial $\mathrm{J}$, numeradas na sequência em que as entrevistas ocorreram, seguidas da inicial $\mathrm{U}$, numeradas de acordo com cada uma das cinco unidades de acolhimento das quais provieram.

\section{Instrumentos}

Foram realizadas entrevistas individuais em profundidade orientadas por roteiros semiestruturados elaborados especificamente para este estudo. A construção dos roteiros se deu com base em aspectos investigados por estudos anteriores sobre transição entre o acolhimento institucional e a vida independente (Del Valle, Bravo, Alvarez, \& Fernanz, 2008; Del Valle, Lázaro-Visa, López, \& Bravo, 2011). 


\section{Procedimentos de Coleta e Análise dos Dados}

A condução desta pesquisa foi autorizada pelo Comitê de Ética do Instituto de Psicologia/UFRGS, sob o parecer de $\mathrm{n}^{\circ} 1534918$. O contato com as instituições de acolhimento foi realizado mediante autorização da Fundação de Ação Social (protocolo 01058740/2016). As instituições participantes assinaram o Termo de Concordância da Instituição e indicaram jovens egressos com os quais mantinham contato. Todos os participantes assinaram Termo de Consentimento Livre e Esclarecido (TCLE).

Os dados foram submetidos à análise temática, com auxílio do software NVivo, seguindo seis passos descritos por Braun e Clarke (2006). Após a transcrição das entrevistas, a análise teve início com a leitura exaustiva do material transcrito para familiarização com os dados. Na segunda etapa, trechos das entrevistas coma aspectos relevantes para o fenômeno da transição foram selecionados a fim de gerar códigos iniciais. Na terceira etapa, iniciou-se a busca por temas, combinando os diferentes códigos de acordo com suas semelhanças. Os temas foram então agrupados em dois eixos temáticos: fatores de risco e fatores de proteção.

A partir dos eixos principais, na quarta etapa, revisaram-se as combinações dos códigos a fim de garantir a homogeneidade interna e a heterogeneidade externa (Patton, 1990). Com os temas definidos refinaram-se também os subtemas. A quinta etapa envolveu nomear os temas e subtemas identificando a essência de cada um e a relação dos mesmos com o todo. Na sexta e última etapa, redigiram-se os resultados. As etapas um a quatro foram conduzidas pela pesquisadora principal. Ao final da quarta etapa, outros dois pesquisadores revisaram os temas e subtemas e sua relação com os dados. As divergências foram discutidas e resolvidas por consenso.

\section{Resultados}

De forma geral, os jovens que participaram deste estudo viviam de forma autônoma e não apresentavam comportamentos de risco ligados a consumo ou tráfico de drogas ou conflito com a lei. À exceção de quatro participantes, todos trabalhavam ou estudavam, contribuíam para o orçamento familiar ou eram os únicos responsáveis pelo mesmo. Dos jovens que trabalhavam, três estavam empregados nas próprias instituições onde estiveram acolhidos. Dos que estudavam, dois cursavam graduação em instituições de ensino privadas e três estavam terminando o Ensino Médio em escolas estaduais. 
No que se refere à história de acolhimento e desligamento dos participantes, o tempo de acolhimento variou entre quatro e dezessete anos, sendo que seis jovens passaram mais de nove anos acolhidos. A maioria viveu em abrigos institucionais e apenas dois em casas-lares. Para somente três dos jovens entrevistados a modalidade de acolhimento em república (moradia de transição) estava disponível quando completaram 18 anos.

Considerando que o objetivo deste estudo foi identificar os fatores de proteção e de risco para o processo de transição, os resultados estão organizados em dois eixos: proteção e risco. Na Tabela 2, apresentam-se os temas e subtemas contidos em cada eixo, resultantes da análise temática. A Figura 1 ilustra um modelo ecológico obtido a partir dos fatores envolvidos no processo de transição. A seguir, descrevem-se cada um dos subtemas e as características que os localizam no eixo de risco ou de proteção. 
Tabela 2

Eixos Temáticos, Temas e Subtemas

\begin{tabular}{|c|c|c|}
\hline Eixo Temático & Temas & Subtemas \\
\hline \multirow[t]{11}{*}{ Fatores de Proteção } & Religiosidade & \\
\hline & Características & Altruismo \\
\hline & pessoais & Autoconceito \\
\hline & & Talento Hobby \\
\hline & Apoio Social & Apoio emocional \\
\hline & & Apoio informacional \\
\hline & Recursos para & Auxilio financiero \\
\hline & vida autônoma & Trabalho \\
\hline & & Formação profissional \\
\hline & & Habilidades de vida cotidiana \\
\hline & & Moradia de transição \\
\hline \multirow[t]{18}{*}{ Fatores de Risco } & Apoio Social & Cuidado como profissão \\
\hline & Insuficiente & Relações familiares complexas e não suportivas \\
\hline & & Rupturas resultantes do desligamento \\
\hline & & Solidão \\
\hline & Fragilidade & \\
\hline & Emocional & \\
\hline & Funcionamento & Falta de acompanhamento após a saída \\
\hline & do Sistema de & Instabilida de do cuidado \\
\hline & Proteçào & Não participação do adolescente na tomada de decisão \\
\hline & & Pouco contato com a realidade fora das instituiçöes \\
\hline & & Poucas ocasiōes para exercer habilidades de vida cotidiana \\
\hline & & Responsabilidade pelo sucesso atribuida ao adolescente \\
\hline & & Saida compulsória a os 18 anos \\
\hline & Oportunidades & Depender da ajuda dos outros \\
\hline & restritas & Falta de moradias de transição \\
\hline & & Dificil acesso ao ensino superior \\
\hline & & Trabalho escasso e não qualificado \\
\hline & & Comportamentos de risco como altemativa de vida \\
\hline
\end{tabular}

\section{Fatores de proteção}

Apoio social. O apoio social foi enfatizado por todos os entrevistados como fator essencial para o enfrentamento da transição. Dois tipos de apoio foram destacados, o 
emocional e o informacional. No apoio emocional, estão todas as fontes de cuidado que os jovens descreveram como afetivamente disponíveis. Já o apoio informacional revelou-se nos relatos sobre conselhos, incentivo e autoafirmação recebida.

As fontes de apoio emocional foram classificadas em: adultos de referência, pares, profissionais e comunidade religiosa. Adultos de referência eram educadores e membros das equipes, mães ou pais sociais, voluntários, padrinhos afetivos e professores com os quais os jovens contavam e cujas atitudes os inspiravam. O apoio de pares vinha de amigos, relacionamentos amorosos e, em poucos casos, dos irmãos. Os profissionais citados como fontes de apoio eram psicólogos e assistentes sociais. Por fim, a vida comunitária, proporcionada pela vinculação com a Igreja, também foi destacada como fonte de suporte para alguns.

O apoio informacional era oferecido principalmente por adultos de referência e apresentou três características marcantes: a escuta ativa, o favorecimento do protagonismo e a imposição de limites e regras. A escuta permeada pela confiança, autoafirmação e cuidado, foi destacada como importante fator protetivo, assim como atitudes suportivas que permitiram aos jovens fortalecer crenças em suas próprias capacidades.

Características pessoais. O altruísmo, o autoconceito positivo e os talentos apresentados por alguns dos jovens foram características individuais que se destacaram como fatores de proteção. Esteve bastante presente nos discursos a vontade de oferecer a outros jovens, e a seus próprios filhos, oportunidades de vida melhores do que aquelas que tiveram: "E meu sonho também é construir um espaço onde eu possa atender os meninos. (...) como se fosse uma república, onde eu possa atender meninos maiores de 18 anos" J2U1. Os jovens cujas trajetórias estiveram permeadas por menos risco foram também os que descreveram mais virtudes próprias.

Outra característica dos que apresentaram resultados mais positivos após a saída do acolhimento foi a presença de talentos para atividades como artes plásticas, artes cênicas, música e futebol. Os talentos foram incentivados durante o acolhimento e ofereceram aos jovens oportunidades fora do contexto institucional. Dois dos jovens entrevistados utilizavam seus talentos como fontes de renda desde que foram desligados.

Religiosidade. Práticas religiosas e a participação em grupos ligados a diferentes religiões foram apontadas pelos jovens como importantes recursos para o enfrentamento das dificuldades após o desligamento. Um dos jovens relatou que em muitas ocasiões a fé e a oração cumpriram o papel de apoio que não foi oferecido por figuras parentais. Uma jovem afirmou que frequentar a Igreja ajudou seu companheiro a manter-se afastado das drogas. 
Recursos para a vida autônoma. A aquisição de habilidades de vida cotidiana, bem como o acesso a recursos mínimos como trabalho, moradia, formação profissional e auxílios financeiros, facilitou enormemente o processo de transição, de acordo com os entrevistados. Parte desses recursos foi obtida ainda durante o acolhimento, como o treino de habilidades para a vida cotidiana: "A gente ajudava a tia na cozinha, a gente lavava a louça, a gente secava... Foi muito bom isso porque foi um aprendizado do que a gente vive aqui fora, entendeu?" J8U4. A formação profissional em muitos casos começou a ser oferecida dentro das instituições, através de cursos profissionalizantes e, para alguns jovens, culminou na obtenção de bolsas de estudo.

Recursos financeiros frutos de poupanças ou de programas governamentais, como o Programa do Leite das Crianças e o Bolsa Família, ofereceram aos jovens a possibilidade de arcar com suas despesas quando não dispunham de outras fontes de renda. Apenas duas jovens entrevistadas usufruíam desses benefícios.

Muitas referências foram feitas à importância do trabalho para o processo de transição. Os entrevistados afirmaram que além de garantir a subsistência, o trabalho fortalece a autoestima e mantém os jovens afastados de comportamentos de risco: "Tipo, cara, eu tenho meu dinheiro! Você se se sentindo útil, entendeu?”J6U1. Alguns jovens tiveram nas próprias instituições de acolhimento seus primeiros empregos e apontaram essa oportunidade como algo positivo.

Um último aspecto citado como importante recurso foi a garantia de um local para morar após o desligamento. Mesmo os jovens que não tiveram oportunidade de viver em repúblicas durante a transição acreditam que elas são fundamentais: "A maioria dos meninos que morou na república conseguiram se preparar melhor para o mundo" J4U1.

\section{Fatores de risco}

Apoio social insuficiente. A falta de apoio social foi citada amplamente pelos jovens e cuidadores, especialmente no que se refere ao apoio familiar. Dos treze jovens, seis disseram não manter contato com a família de origem. O subtema relações familiares complexas e não suportivas contém a busca pelo suporte dos familiares, a dependência de alguns pais em relação aos jovens e a fragilidade das relações entre os irmãos: “(...) ele [pai] saiu do tratamento [para alcoolismo] e não tinha mais casa (...) daí quando comecei a construir minha casa eu já comecei a construir um espaço pra ele” J2U1. 
Embora os jovens tenham vivido a maior parte de suas vidas junto aos irmãos, acolhidos nas mesmas instituições, a vinculação muitas vezes não se manteve na vida adulta. As rupturas resultantes do desligamento referiram-se também às quebras de vínculos com cuidadores, funcionários e pares. Os discursos revelaram o impacto negativo do distanciamento dessas figuras.

Uma distinção foi feita pelos entrevistados entre os educadores que encaravam o cuidado como profissão e os que de fato se preocupavam com o futuro dos seus educandos. Uma jovem afirmou que a maioria dos adolescentes "mora na casa do pessoal, mas não se sente família" J13U5 e a assistente social dessa mesma unidade alegou que os adolescentes veem a mãe-social "como se fosse uma doméstica, um serviçal, que está ali para servi-los" C2U5. Diante da falta de suporte social muitos descreveram sentimentos de solidão. Nesse subtema as falas expressaram a tristeza dos jovens por estarem sozinhos, assim como a angústia dos cuidadores ao terem que desligar adolescentes que não tinham com quem contar.

Fragilidade emocional. Comportamentos de fuga e evitação, imaturidade e sentimentos de medo e abandono foram citados como razões do despreparo para o desligamento. De acordo com os entrevistados, a necessidade de restauração de si e do sofrimento vivido interferiram na escolaridade e na possibilidade de engajar-se em atividades complementares. A diretora de uma unidade afirmou que trabalhar os aspectos emocionais é uma das principais necessidades, já que antes de instrumentalizar os jovens para a saída eles precisam “(...) resolver o problema da mãe dele que deixou, o pai que nunca conheceu, os abusos que eles sofreram" C4U1.

Funcionamento do sistema de proteção. Os jovens enfatizaram que a saída compulsória aos 18 anos não considera as especificidades de cada caso, já que muitos adolescentes não querem deixar as instituições e não tem para onde ir: "O adolescente completa 18 anos ele é chutado da instituição, assim, sabe? Cara, você fez 18 anos, você não é mais responsabilidade do Estado, se dane" J3U1. Por parte dos cuidadores, a obrigatoriedade do desligamento aos 18 também foi questionada: "Completou dezoito tem que dar um jeito.... Não! Eu assumo toda a responsabilidade até o dia que elas estiverem preparadas para sair" C5U4.

A falta de acompanhamento após a saída evidenciou-se na situação de um jovem que, ao buscar apoio da unidade onde vivia para retomar os estudos após o desligamento, obteve como resposta que não poderiam ajuda-lo: "A hora que eu vi que não iam me ajudar, eu já falei: 'Ó, tá sendo difícil sozinho"” J12U1. Enquanto os jovens se referiram às consequências de não receberem acompanhamento, alguns cuidadores lamentaram não poder 
realizá-lo: "A gente não tem pernas para conseguir atender muito mais do que os nossos, entende?" C4U1.

A instabilidade do cuidado foi outra dificuldade relativa ao funcionamento que na opinião dos entrevistados interferiu na preparação para o desligamento. Os jovens relataram que as mudanças de casa dificultavam a formação de vínculos afetivos: "A gente ficava dois meses em uma casa, cinco na outra (...) Isso daí eu acho meio ruim para as crianças porque mexe com o emocional das crianças..." J13U5. Mudanças de equipe também foram citadas pelos cuidadores como prejudiciais, não só pela quebra de vinculação, mas pela descontinuidade dos planos de trabalho.

Outros dois aspectos citados, relativos a falhas no funcionamento, foram a não participação do adolescente na tomada de decisão e a responsabilidade pelo sucesso atribuída ao adolescente. Os jovens relataram a necessidade de aceitar as poucas oportunidades disponíveis, mesmo que não fossem do seu interesse. Ao mesmo tempo, seus relatos revelaram a concepção de que são eles próprios os responsáveis pela preparação e transição. Uma educadora também afirmou que nem todos os adolescentes sabem tirar proveito das oportunidades: "Eu acho que só vai pra frente quem tem uma vontade de ir pra frente. Não adianta você querer me ajudar e eu não me ajudar também” C1U3.

Sobre falhas do processo de preparação para a saída, dois aspectos foram identificados, que os adolescentes possuem pouco contato com a realidade fora das instituições e que são poucas as ocasiões para exercer atividades da vida cotidiana. $O$ desligamento para alguns veio acompanhado de surpresa com vida com a qual se depararam: "Na verdade eu era muito virgem de tudo, assim... Não sabia de nada, nada! Aí foi bem difícil assim, saí de uma realidade e fui pra outra” J6U1.

Oportunidades restritas. O cenário com o qual os jovens se depararam ao deixar o acolhimento foi de falta de oportunidades. No ato do desligamento, a falta de moradias de transição (repúblicas) obrigou as instituições a buscar por moradia para os jovens de acordo com os recursos disponíveis em cada ocasião: "Nem sempre as vagas existem da forma que a gente quer. Então a gente consegue aloca-los ou nas famílias ou nas... Principalmente nas ONGs, que são mais receptivas" C3U2.

No subtema trabalho escasso e não qualificado, estão contidos os relatos sobre a dificuldade de conseguir trabalho pela baixa escolaridade e sobre a precariedade e informalidade das vagas existentes. Para as mulheres, a conquista de um emprego esteve ainda atrelada à disponibilidade de vagas nas creches, direito que nem sempre foi garantido. Para aqueles que concluíram o Ensino Médio, o plano de ingressar na Universidade esbarrou 
em limitações para pagar pelo ensino superior e/ou de reduzir a jornada de trabalho para continuar os estudos.

Com tantos entraves para o enfrentamento da vida adulta, duas alternativas foram apontadas como estratégias para subsistência: comportamentos de risco e dependência da ajuda de outros. Os jovens que dependiam de outros, estavam descontentes com essa posição: "Eu sempre estou dependendo dos outros. É muito ruim isso" J10U5. Esta jovem explicou que embora depender dos outros não fosse ideal, preferiu esta alternativa a envolverse em atividades ilícitas para buscar seu sustento.

As histórias de vida da maioria dos jovens estavam marcadas pelos comportamentos de risco de familiares, tendo três deles revelado envolvimento com drogas e tráfico no passado. Os entrevistados afirmaram que o caminho da "marginalidade" muitas vezes era mais viável e oferecia benefícios mais imediatos. Foram inúmeros os relatos sobre egressos que estavam presos, mortos ou em situação de rua: "De 2009 pra cá já perdi três primos meus que, né, tava envolvido com tráfico aí. O único que restou só fui eu e outro primo meu...” J1U1. 


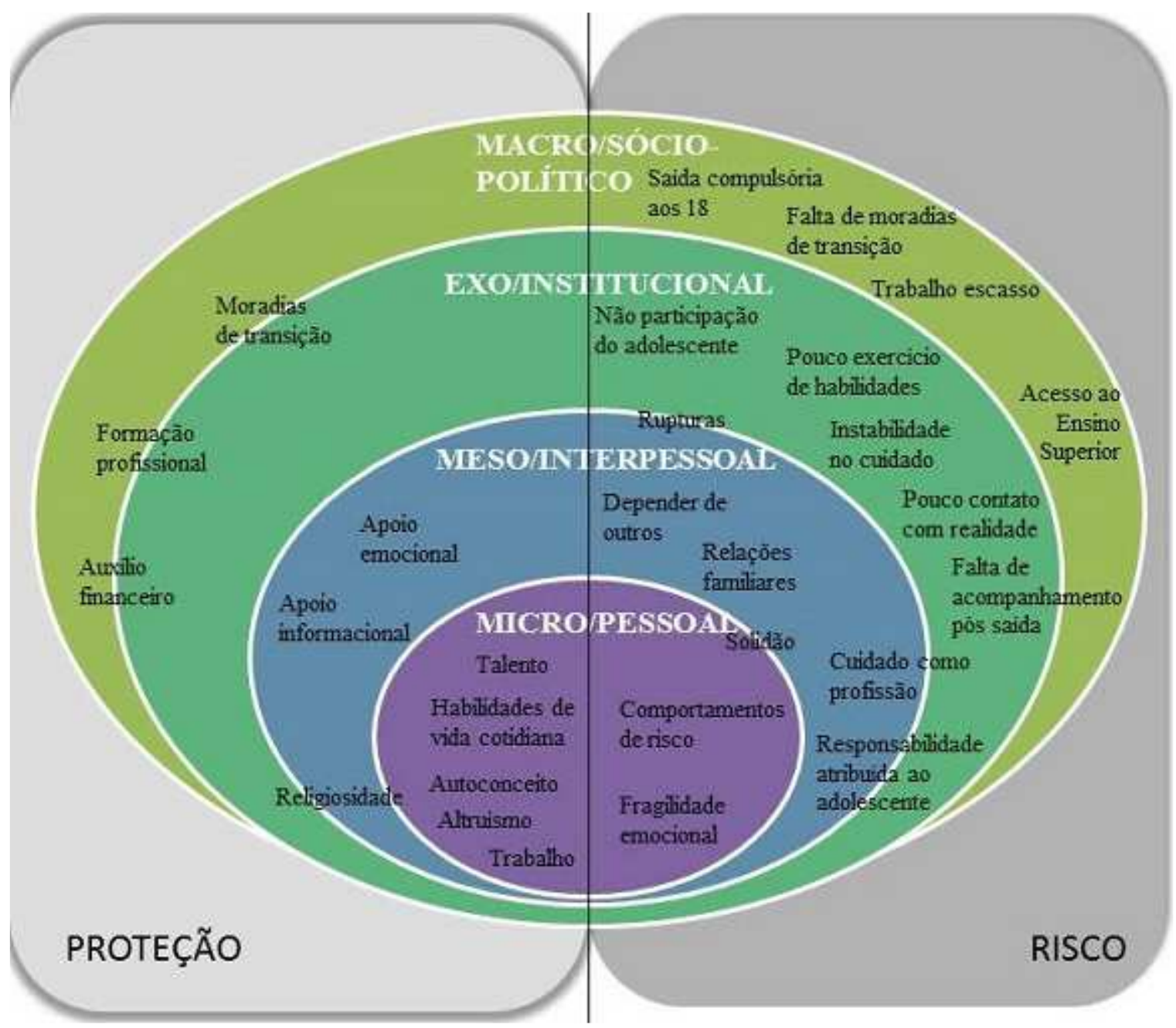

Figura 1. Modelo ecológico obtido a partir dos fatores de risco e de proteção encontrados

\section{Discussão}

Este estudo empregou a análise temática para investigar fatores de proteção e de risco no processo de transição entre o acolhimento institucional e a vida adulta de jovens egressos do sistema de proteção. Como resultado, obteve-se um mapeamento dos fatores vivenciados, contemplando diferentes níveis contextuais, incluindo: individual, interpessoal, institucional e sócio-político. A análise dos resultados reforçou o caráter ecológico do processo vivido por estes jovens, e a necessidade de preparação e desenvolvimento de recursos para a resolução desta etapa de forma saudável e com menos estresse psicossocial (Sarriera, 2014b).

Embora todos os fatores interajam entre si, perpassando diferentes níveis contextuais, alguns estão mais restritos ao nível individual, como é o caso das características pessoais de autoconceito positivo, altruísmo, religiosidade e fragilidade emocional. Fatores de proteção são dinâmicos e podem variar a depender do contexto e do momento de vida de casa pessoa. No entanto, a literatura destaca características de personalidade como fatores de proteção mais 
estáveis e amplamente influenciadores dos resultados frente a adversidades (Bonanno, Romero, \& Klein, 2015). Aspectos relacionados à identidade, como o autoconceito e a autoeficácia, são componentes essenciais para que o jovem possa se sentir capaz de planejar e cumprir metas, além de ressignificar vivências traumáticas (Stein, 2005).

Sentimentos de gratidão, reconhecimento do sofrimento do outro e atitudes altruístas são características pessoais que têm como consequência emoções positivas de felicidade, orgulho e esperança que motivam o comportamento e favorecem a resiliência (Cyrulnik, 2005; Emmons \& Shelton, 2002). Associadas a elas, os participantes desse estudo relataram crenças e práticas religiosas e como estas contribuem para enfrentar os desafios da vida autônoma. Gratidão, altruísmo e empatia são valores fomentados em religiões, e que contribuem na inibição do engajamento em comportamentos de risco (Scott, Hodge, White, \& Munson, 2018).

As características pessoais positivas ajudam a fazer frente à fragilidade emocional, causada pelas histórias pessoais de vulnerabilidade. Problemas de saúde mental estão entre os fatores de risco, de nível individual, mais salientados por estudos sobre a transição entre o acolhimento e a vida adulta (Courtney, Hook, \& Lee, 2012; Scannapieco, Smith, \& BlakeneyStrong, 2016). Pesquisadores reforçam a prioridade do acompanhamento psicológico e psiquiátrico das crianças e adolescentes acolhidos, através de serviços de saúde mental de alta qualidade, essenciais para a promoção do bem-estar psicossocial (Pecora, 2010).

As histórias de vida permeadas por risco são carregadas individualmente pelos jovens, porém, são consequências de suas relações interpessoais. Ausência de apoio parental e familiar, bem como conflitos familiares, estão na raiz da vulnerabilidade destes jovens (Courtney, Hook, \& Lee, 2012; Greeson, 2013; Scannapieco, Smith, \& Blakeney-Strong, 2016). Os resultados do presente estudo revelam que, embora a medida de acolhimento deva priorizar a reunificação (Lei n. 8069, 1990), durante a institucionalização ocorre o enfraquecimento dos vínculos familiares.

Já que a coesão familiar dificilmente encontra lugar na história dos jovens egressos, outras fontes de vinculação afetiva precisam ser incorporadas à rede de suporte (Cyrulnik, 2005). O papel substitutivo pode ser exercido por educadores ou mães/pais sociais, que ocupam lugar central de cuidado e de vinculação afetiva durante e após o acolhimento. No entanto, aqueles que têm no cuidado uma profissão, falham em atender as necessidades afetivas de seus educandos (Masten \& Garmenzy, 1985). Os cuidadores que participaram deste estudo e foram apontados como figuras de referência, apresentam em comum o interesse genuíno pelos acolhidos e um olhar individualizado. Quando essas características permeiam o 
cuidado, a postura ativa do jovem na busca de estratégias para solucionar problemas tende a ser reafirmada, funcionando como motor promotor de resiliência (Werner, 1995).

O apoio genuíno e individualizado também foi oferecido, de acordo com os jovens, por outros adultos que não fazem parte das equipes do acolhimento, como padrinhos, professores e voluntários. São figuras que a literatura recente intitula como "mentores", não somente por serem exemplos a seguir, mas também por oferecem conselhos e instrumentalização (Greeson, 2013). Essas relações em alguns casos se estabelecem espontaneamente, mas em outros ocorrem por incentivo das equipes das unidades. A relação com esses adultos tem como característica a confiança que facilita a oferta de uma escuta ativa e consistente (Osterling \& Hines, 2006).

A importância da postura dos cuidadores e profissionais na preparação do jovem para a saída tem sido pauta de estudos e discussões recentes (Eastman, Putnam-Hornstein, Magruder, Mitchell, \& Courtney. 2017). Barros e Naiff (2015) discutem que a capacitação desses agentes precisa perpassar diferentes níveis contextuais, sendo oferecida a todos como parte de políticas públicas, sem deixar de atender às necessidades específicas de cada unidade. Orionte e Sousa (2005) entendem que é necessário superar a perspectiva adultocêntrica e dar "voz" as crianças acolhidas. Os resultados do presente estudo apontam para as mesmas lacunas identificadas por esses autores e reforçam a necessidade de cuidadores construtores de subjetividade, evitando que o jovem saia da instituição acreditando ser dele a culpa por falhas e eventuais frustrações.

Também de acordo com os resultados obtidos, outros aspectos de nível institucional interferem negativamente no processo de transição. A quantidade de crianças e adolescentes por unidade de acolhimento é um deles. No Brasil, onde $74 \%$ dos acolhidos estão em abrigos institucionais (MDS, 2015), com proporção de até um educador para cada 10 educandos (CNA \& CNAS, 2008), o cuidado individualizado está certamente comprometido. Interferem ainda na qualidade do cuidado, de acordo com os participantes deste estudo, a rotatividade de cuidadores e as transferências de uma unidade para outra. Outros estudos com participantes em situação de acolhimento já revelaram que mudanças de cuidadores, casa, escola e amigos impactam significativamente o bem-estar destas crianças e adolescentes (Montserratet al., 2015).

Avançar no reordenamento das unidades de acolhimento, com vistas a diminuir o número de acolhidos por unidade e aumentar o número de famílias acolhedoras (CNA \& CNAS, 2008) é necessário para que se possa melhorar a qualidade da preparação para a vida adulta. Não só pela urgência de relações de cuidado mais individualizadas e menos instáveis, 
mas porque serviços menores ou famílias substitutas possibilitam maior interação do acolhido com a realidade. É de fundamental importância que o adolescente circule por diferentes contextos, a fim de experimentar situações que propiciem o treino de habilidades para resolver problemas, característica pessoal essencial para o enfrentamento de adversidades (Masten \& Garmenzy, 1985). O contato com a realidade fora do acolhimento também pode ser oferecido através de programas complementares de fortalecimento da rede de apoio (Goyette et al., 2016; Nesmith \& Christophersen; 2014) e treinamento de habilidades para a vida cotidiana (Greeson et al., 2015; Kirk \& Day, 2011; Okpych, 2015). Programas para favorecer a transição são muito comuns em diversos países, mas no Brasil ainda são incipientes.

Oportunidades dessa natureza precisam ser oferecidas a todos os jovens, como parte de políticas voltadas especificamente para eles. A ausência de respaldo para que o jovem transite do acolhimento para a vida adulta é revelada neste estudo, não só pela falta de programas de preparação, mas pela carência de moradias de transição. As repúblicas estão dentre as modalidades de acolhimento previstas por lei que deveriam oferecer ao adolescente apoio técnico e espaços de escuta e construção de projetos de vida (Brasil, 2008).

Os benefícios de prolongar o tempo de permanência no sistema de proteção têm sido amplamente demonstrados e discutidos por pesquisadores e formuladores de políticas públicas (Courtney, Hook, \& Lee, 2012; Scannapieco, Smith, \& Blakeney-Strong, 2016). Estudo longitudinal com 732 egressos nos Estados Unidos demonstrou que cada ano a mais no sistema de proteção aumenta em $46 \%$ as chances de continuidade dos estudos, diminuindo, consequentemente, as taxas de desemprego (Courtney \& Hook, 2017). A empregabilidade, as dificuldades financeiras e a interrupção dos estudos estão entre os principais desafios relatados pelos jovens egressos do sistema de proteção em Curitiba.

Assim como apontam os estudos internacionais, os participantes desta pesquisa entendem a continuidade do amparo para além dos 18 anos como um fator de proteção importante para a conquista de resultados positivos a médio e longo prazo. No Brasil, a condição de vulnerabilidade dos jovens egressos parece não constituir fundamento suficiente para garantir-lhes a posição de beneficiários durante a transição. Em alguns municípios e estados, projetos de lei que preveem benefícios para essa população já foram apresentados, embora não tenham saído do papel (Bugalho, 2018; Correa, 2013; Perugini, 2013). 


\section{Considerações Finais}

A análise aprofundada dos fatores de risco e de proteção em diferentes níveis contextuais permitiu observar um desequilíbrio que dificulta o processo de transição. $\mathrm{O}$ esquema apresentado na Figura 1 revela que os fatores de risco estão distribuídos nos níveis individual, interpessoal, institucional e sócio-político, enquanto que fatores de proteção tendem a concentrar-se nos níveis individual e interpessoal (quando muito, na relação entre unidades de acolhimento e apoiadores externos). Como consequência, tem-se que as oportunidades existentes são usufruídas principalmente pelos adolescentes que apresentam determinadas características pessoais e/ou cujas histórias de vida apresentam menos risco. Esse movimento reforça a vulnerabilidade da maioria, ao invés de oferecer a todos boas condições de enfrentar a vida após o desligamento. Os jovens que demonstram talentos ou interesses específicos acabam sendo orientados à formação e à profissionalização, obtendo melhor desempenho no processo de transição. Enquanto isso, os muitos jovens que mal conseguem completar o ensino obrigatório estão destinados a empregos não qualificados, dependência de outros ou comportamentos de risco como alternativas para subsistência.

A falta de serviços e políticas públicas destinadas à população jovem com história de acolhimento institucional no Brasil deposita nos ombros dos egressos a responsabilidade pelo sucesso de seus processos de transição. Foi possível verificar a necessidade urgente de promoção de fatores proteção de macro e exo contexto a fim de favorecer o desligamento e os resultados futuros de adolescentes acolhidos. Nesse sentido, dois caminhos precisam ser percorridos: (1) o da observância às leis e diretrizes já existentes (desligamento gradual; capacitação dos cuidadores; implantação de repúblicas; reordenamento das unidades; e aumento do número de famílias acolhedoras) e (2) o da formulação de programas e políticas públicas específicas para esta população (treinamento de habilidades de vida cotidiana; aproximação a mentores; bolsas de auxílio financeiro).

Este estudo revelou ainda a importância de que as mudanças ocorram alicerçadas na concepção de que o jovem deve ser protagonista do seu próprio processo. Quanto maior for o papel dos jovens na tomada de decisões sobre seus planos de futuro, maiores as possibilidades de que programas e políticas destinadas a eles sejam efetivas.

Ainda há muito a ser investigado sobre a transição para a vida adulta no contexto do sistema de proteção brasileiro, de modo que é imprescindível continuar avançando na produção de conhecimento neste campo. A superação de algumas das limitações deste estudo pode contribuir para esse avanço. Destaca-se a limitação referente à dificuldade em acessar 
egressos do acolhimento em situação de extrema vulnerabilidade. Incluir esses jovens em futuros estudos permitirá uma compreensão mais aprofundada dos fatores de risco envolvidos no processo de transição. Outra limitação que precisa ser superada é a excessiva burocratização para autorização de pesquisas no contexto da proteção especial. Simplificar o acesso às instituições, por parte pesquisadores experientes e eticamente comprometidos, favorecerá a condução de estudos longitudinais necessários para melhor compreendermos, não só o processo de transição para a vida adulta, mas diversos outros aspectos relacionados ao acolhimento no Brasil.

\section{Referências}

Amstadter, A. B., Moscati, A., Maes, H. H., Myers, J. M., \& Kendler, K. S. (2016). Personality, cognitive/psychological traits and psychiatric resilience: A multivariate twin study. Personality and Individual Differences, 91, 74-79. doi:10.1016/j.paid.2015.11.041

Barros, N. S., \& Naiff, L. A. M. (2015). Capacitação para educadores de abrigo de crianças e adolescentes: Identificando representações sociais. Estudos e Pesquisas em Psicologia, 15(1), 240-259. Recuperado de https://www.epublicacoes.uerj.br/index.php/revispsi/article/view/16073/12092

Bender, K., Yang, J., Ferguson, K., \& Thompson, S. (2015). Experiences needs of homeless youth with a history of foster care. Children and Youth Services Review, 55, 222-231. doi:10.1016/j.childyouth.2015.06.007

Bonanno, G. A., Romero, S. A., \& Klein, S. I. (2015). The temporal elements of psychological resilience: An integrative framework for the study of individuals, families, and communities. Psychological Inquiry, 26(2), 139-169. doi:10.1080/1047840X.2015.992677

Brasil (1990, Julho 13). Lei no. 8.069. Dispõe sobre o Estatuto da Criança e do Adolescente e dá outras providências. Brasília, DF: Presidência da República. Recuperado de http://www.planalto.gov.br/ccivil_03/leis/18069.htm

Braun, V., \& Clarke, V. (2006). Using thematic analysis in psychology. Qualitative Research in Psychology, 3(2), 77-101. doi:10.1191/1478088706qp063oa

Brito, R., \& Koller, S. H. (1999). Desenvolvimento humano e redes de apoio social e afetivo. In A. M. Carvalho (Ed.), O mundo social da criança: Natureza e cultura em ação (pp. 115-129). São Paulo, Brasil: Casa do Psicólogo. 
Bugalho, N. R. (2018). Projeto de Lei no. 58/2018, de 16 de abril de 2018. Institui a Bolsa Serviço de Acolhimento em República no Município de Presidente Prudente. Presidente Prudente, SP: Câmara Municipal de Presidente Prudente.

Camarano, A., Mello, J., Pasinato, M., \& Kanso, S. (2004). Caminhos para a vida adulta: As múltiplas trajetórias dos jovens brasileiro. Ultima Década, 12(21), 11-50. doi:10.4067/S0718-22362004000200002.

Conselho Nacional da Criança e do Adolescente [CNA], \& Conselho Nacional de Assistência Social [CNAS]. (2008). Orientações técnicas para os serviços de acolhimento para crianças e adolescentes. Brasília, DF. Recuperado de http://www.mds.gov.br/cnas/noticias/orientacoes_tecnicas_final.pdf

Correa, A. (2013). Projeto de Lei no 2.473, de 26 de setembro de 2013. Institui o Programa "Depois do Abrigo". Recuperado de http://alerjln1.alerj.rj.gov.br/scpro1115.nsf/18c1dd68f96be3e7832566ec0018d833/01b 7f55fc8add8de83257bea00502ec1?OpenDocument\&ExpandSection=-1

Courtney, M. E., \& Hook, J. L. (2017). The potential educational benefits of extending foster care to young adults: Findings from a natural experiment. Children and Youth Services Review, 72, 124-132. doi:10.1016/j.childyouth.2016.09.030

Courtney, M. E., Hook, J. L., \& Lee, J. S. (2012). Distinct subgroups of former foster youth during young adulthood: Implications for policy and practice. Child Care in Practice, 18(4), 409-418. doi:10.1080/13575279.2012.718196

Cyrulnik, B. (2005). The whispering of ghosts: Trauma and resilience. New York, NY: Other Press.

Del Valle, J. F., Bravo, A., Alvarez, E., \& Fernanz, A. (2008). Adult self-sufficiency and social adjustment in care leavers from children's homes: A long term assessment. Child \& Family Social Work, 13(1), 12-22. doi:10.1111/j.1365-2206.2007.00510.x

Del Valle, J. F., Lázaro-Visa, S., López, M., \& Bravo, A. (2011). Leaving family care. Children and Youth Services Review, 33(12), 2475-2481. doi:10.1016/j.childyouth.2011.08.015

Eastman, A. L., Putnam-Hornstein, E., Magruder, J., Mitchell, M. N., \& Courtney, M. E. (2017). Characteristics of youth remaining in foster care through age 19: A pre-and post-policy cohort analysis of California data. Journal of Public Child Welfare, 11(1), 40-57. 
Emmons, R. A., \& Shelton, C. M. (2002). Gratitude and the science of positive psychology. In C. R. Snyder \& S. J. Lopez (Eds.), Handbook of positive psychology (pp. 459-471). New York: Oxford University Press.

Forsman, H., Brännström, L., Vinnerljung, B., \& Hjern, A. (2016). Does poor school performance cause later psychosocial problems among children in foster care? Evidence from national longitudinal registry data. Child Abuse \& Neglect, 57, 61-71. doi:10.1016/j.chiabu.2016.06.006

Goyette, M., Mann-Feder, V., Turcotte, D., \& Grenier, S. (2016). Youth empowerment and engagement: An analysis of support practices in the youth protection system in Québec. Revista Española de Pedagogía, 74, 31-49. Recuperado de https://www.jstor.org/stable/24711267

Greeson, J. (2013). Foster youth and the transition to adulthood the theoretical and conceptual basis for natural mentoring. Emerging Adulthood, 1(1), 40-51. doi:10.1177/2167696812467780

Greeson, J. K., Garcia, A. R., Kim, M., \& Courtney, M. E. (2015). Foster youth and social support: The first RCT of independent living services. Research on Social Work Practice, 25(3), 349-357. doi:10.1177/1049731514534900

Hass, M., \& Graydon, K. (2009). Sources of resiliency among successful foster youth. Children and Youth Services Review, 31(4), 457-463. doi:10.1016/j.childyouth.2008.10.001

Kelly, J. G. (1986). An ecological paradigm: Defining mental health consultation as a preventive service. Prevention in the Human Services, 4(3-4), 1-36. doi:10.1300/J293v04n03_01

Kirk, R., \& Day, A. (2011). Increasing college access for youth aging out of foster care: Evaluation of a summer camp program for foster youth transitioning from high school to college. Children and Youth Services Review, 33(7), 1173-1180. doi:10.1016/j.childyouth.2011.02.018

Libório, R. M. C., \& Ungar, M. (2010). Resiliência oculta: A construção social do conceito e suas implicações para práticas profissionais junto a adolescentes em situação de risco. Psicologia Reflexão e Crítica, 23(3), 476-484. doi:10.1590/S010279722010000300008

Martinez, A. L. M., \& Soares-Silva, A. P. (2008). O momento da saída do abrigo por causa da maioridade: A voz dos adolescentes. Psicologia em Revista, 14(2), 113-132. Recuperado 
https://www.researchgate.net/publication/257362647_O_momento_da_saida_do_abrig o_por_causa_da_maioridade_a_voz_dos_adolescentes

Masten, A. (2001). Ordinarymagic: Resilience processes in development. American Psychologist, 56(3), 227-238. doi:10.1037/0003-066X.56.3.227

Masten, A. S., \& Garmezy, N. (1985). Risk, vulnerability, and protective factors in developmental psychopathology. In B. Lahey (Ed.), Advances in clinical child psychology (pp. 1-52). Boston, MA: Springer.

Ministério de Desenvolvimento Social e Combate à Fome [MDS]. (2015). Censo SUAS 2014. Brasília, DF: MDS, Secretaria de Avaliação e Gestão da Informação; Secretaria Nacional de Assistência Social. Recuperado de https://www.mds.gov.br/webarquivos/publicacao/assistencia_social/Livros/Censo\%20 SUAS\%202014.pdf

Montserrat C., Dinisman T., Baltatescu S, Grigoras B. A., \& Casas F. (2015). The effect of critical changes and gender on adolescents' subjective well-being: Comparisons across 8 countries. Child Indicators Research, 8(1), 111-131. doi:10.1007/s12187-014-92889

Neal, D. (2017). Academic resilience and caring adults: The experiences of former foster youth. Children and Youth Services Review, 79, 242-248. doi:10.1016/j.childyouth.2017.06.005

Nesmith, A. (2017). Coping with change: Using the bridge's transitions framework with foster youth. Children and Youth Services Review, 78(C), 41-47. doi:10.1016/j.childyouth.2017.05.009

Okpych, N. J. (2015). Receipt of independent living services among older youth in foster care: An analysis of national data from the US. Children and Youth Services Review, 51, 74-86. doi: 10.1016/j.childyouth.2015.01.021

Orionte, I., \& Sousa, S. M. G. (2005). O significado do abandono para crianças institucionalizadas. Psicologia em Revista, 11(17), 29-46. Recuperado de http://pepsic.bvsalud.org/pdf/per/v11n17/v11n17a03.pdf

Osterling, K. L., \& Hines, A. M. (2006). Mentoring adolescent foster youth: Promoting resilience during developmental transitions. Child \& Family Social Work, 11(3), 242253. Recuperado de https://onlinelibrary.wiley.com/doi/pdf/10.1111/j.13652206.2006.00427.x

Patton, M. Q. (1990). Qualitative Evaluation and Research Methods (2nd ed.). Newbury Park, CA: Sage Publications. 
Pecora, P. J. (2010). Why current and former recipients of foster care need high quality mental health services. Administration and Policy in Mental Health and Mental Health Services Research, 37(1-2), 185-190. doi:10.1007/s10488-010-0295-y

Perugini, A. (2013). Projeto de Lei n. 439, de 28 de junho de 2013. Institui o Programa de Atendimento Juvenil aos Egressos da Casa Abrigo. Recuperado de https://www.al.sp.gov.br/propositura/?id=1143707

Pinheiro, D. P. N. (2004). A resiliência em discussão. Psicologia em Estudo, 9(1),67-75. doi:10.1590/S1413-73722004000100009

Poletto, M., \& Koller, S. H. (2006). Resiliência: Uma perspectiva conceitual e histórica. In D. D. Dell'Aglio, S. H. Koller, \& M. A. M. Yunes (Eds.), Resiliência e psicologia positiva: Interfaces do risco à proteção (pp. 19-44). São Paulo: Casa do Psicólogo.

Rosa, E. M., Nascimento, C. R. R., Matos, J. R., \& Santos, J. R. dos. (2012). O processo de desligamento de adolescentes em acolhimento institucional. Estudos de Psicologia, 17(3), 361-368. doi:10.1590/S1413-294X2012000300003

Rutter, M. (1985). Resilience in the face of adversity: Protective factors and resistence to psychiatric disorder. British Journal of Psychiatry, 147, 598-611. doi:10.1192/bjp.147.6.598

Sarriera, J. C. (1999). Uma perspectiva da orientação profissional para o novo milênio. Revista $\quad d a \quad$ ABOP, 3(1), 85-96. Recuperado de http://pepsic.bvsalud.org/pdf/rabop/v3n1/v3n1a08.pdf

Sarriera, J. C. (2014a). O paradigma ecológico na psicologia comunitária: Do contexto à complexidade. In J. C. Sarriera \& E. T. Saforcada (Eds.), Introdução à psicologia comunitária: Bases teóricas e metodológicas (pp. 27-47). Porto Alegre: Editora Sulina.

Sarriera, J. C. (2014b). Análise de necessidades de um grupo ou comunidade: A avaliação como processo. In J. C. Sarriera \& E. T. Saforcada (Eds.), Introdução à psicologia comunitária: Bases teóricas e metodológicas (pp. 139-152). Porto Alegre: Editora Sulina.

Scannapieco, M., Smith, M., \& Blakeney-Strong, A. (2016). Transition from foster care to independent living: Ecological predictors associated with outcomes. Child and adolescent social work journal, 33(4), 293-302. doi:10.1007/s10560-015-0426-0

Scott, L. D., Hodge, D. R., White, T., \& Munson, M. R. (2018). Substance use among older youth transitioning from foster care: examining the protective effects of religious and spiritual capital. Child \& Family Social Work, 23(3), 1-9. doi:10.1111/cfs.12429 
Siqueira, A., \& Dell'Aglio, D. (2007). Retornando para a família de origem: Fatores de risco e proteção no processo de reinserção de uma adolescente institucionalizada. Revista Brasileira de Crescimento e Desenvolvimento Humano, 17(3), 134-146. Recuperado de http://pepsic.bvsalud.org/scielo.php?script=sci_arttext\&pid=S010412822007000300014

Stein, M. (2005). Resilience and young people leaving care: overcoming the odds. York, UK: Joseph Rowntree Foundation.

Sulimani-Aidan, Y. (2017). To dream the impossible dream: Care leavers' challenges and barriers in pursuing their future expectations and goals. Children and Youth Services Review, 81(C), 332-339. doi:10.1016/j.childyouth.2017.08.025

Werner, E. E. (1995). Resilience in development. Current directions in psychological science, 4(3), 81-85. doi:10.1111/1467-8721.ep10772327

Wills, T, Blechman, E., \& McNamara, G. (1996). Family support, coping and competence. In M. Hetherington \& E. Blechman (Eds.), Stress, coping and resiliency in children and families (pp. 107-133). New Jersey, USA: Lawrence Erlbaum.

Wojciak, A. S., McWey, L. M., \& Waid, J. (2018). Sibling relationships of youth in foster care: A predictor of resilience. Children and Youth Services Review, 84, 247-254. doi:10.1016/j.childyouth.2017.11.030

\section{Endereço para correspondência}

\section{Luciana Cassarino-Perez}

Rua Ramiro Barcelos, 2600 sala 222, Porto Alegre - RS, Brasil. CEP 90035-003

Endereço eletrônico: lucicaspe@gmail.com

\section{Carme Montserrat}

Plaça Sant Domènec, 9, 17071 sala 338, Girona - España

Endereço eletrônico: carme.montserrat@udg.edu

\section{Jorge Castellá Sarriera}

Rua Ramiro Barcelos, 2600 sala 222, Porto Alegre - RS, Brasil. CEP 90035-003

Endereço eletrônico: jorgesarriera@gmail.com

Recebido em: 15/04/2019

Reformulado em: 18/09/2019

Aceito em: 02/10/2019 


\section{Notas}

* Psicóloga. Mestre e Doutora em Psicologia pela Universidade Federal do Rio Grande do Sul. Coordenadora do Curso de Psicologia da Faculdade de Telêmaco Borba.

** Pedagoga. Mestre em Pedagogia. Doutora em Psicologia. Professora da Faculdade de Psicologia da Universidade de Girona.

*** Psicólogo. Mestre em Psicologia Escolar. Doutor em Psicologia Social. Professor nos PPGs em Psicologia e em Serviço Social da Universidade Federal do Rio Grande do Sul.

Este artigo de revista Estudos e Pesquisas em Psicologia é licenciado sob uma Licença Creative Commons Atribuição-Não Comercial 3.0 Não Adaptada. 